\title{
Novel Synthesis of Linear Polyimides by Palladium-Catalyzed Carbonylation Polycondensation of Aromatic Diamides, Aromatic Dibromides, and Carbon Monoxide
}

\author{
Masaru Yoneyama, ${ }^{\dagger}$ Toshihisa NaSA, and Kozo AraI \\ Department of Biological and Chemical Engineering, Faculty of Engineering, \\ Gunma University, Kiryu, Gunma 376-8515, Japan
}

(Received January 13, 1998)

\begin{abstract}
A new and convenient method was found for the synthesis of linear imides by the palladium-catalyzed carbonylation condensation of aromatic amides with aromatic bromides and carbon monoxide. By the extension of this reaction to polymerization, a novel approach to the preparation of linear polyimides was developed. The effects of polymerization conditions, such as kinds and amounts of base and palladium catalyst, and polymerization temperature are discussed in detail. Large excess $\mathrm{PPh}_{3}$ was required to obtain a homogeneous solution. The reactivity of aromatic diamides was found to be low for this carbonylation polycondensation.

KEY WORDS Palladium Catalysts / Carbonylation Polycondensation /Linear Polyimides / Carbon Monoxide /
\end{abstract}

Wholly aromatic polyimides are found in various high-technology fields such as electronic and aerospace industries owing to their high-use temperature, excellent mechanical and electrical properties, inherent flame resistance, and chemical stabilities. ${ }^{1,2}$ They all have imide groups in the form of cyclic structures in the backbone. However, little is known about the synthesis and properties of aromatic polyimides containing linear (openchain) imide structures ${ }^{3-6}$ due in part to difficulties in preparing linear imides in quantitative yields. Several synthetic routes have been used to produce these polymers. These involve the diacylation of ordinary amines or $O$-substituted hydroxyamines with acid chlorides and the reactions of imidoyl chlorides with carboxylic acids. Common to most synthetic methods is the use of aromatic acid or derivative monomers. The preparation of such monomers requires a number of reaction steps. Moreover, all the polymers obtained by previous methods have $N$-arylated structures.

Amides and esters can be obtained from aromatic halides, carbon monoxide, and nucleophiles, such as amine and alcohols in high yields by palladium catalysts. ${ }^{7,8}$ These reactions have been well documented for not only the formation of amides and esters but also that of $\alpha$-keto amides, ${ }^{9-11} \alpha$-keto esters, ${ }^{12-14}$ anhydrides, ${ }^{15}$ acid fluorides, ${ }^{16}$ lactams, ${ }^{17}$ lactones, ${ }^{18} \mathrm{ke}-$ tones, ${ }^{19}$ phthalimides, ${ }^{20}$ benzoxazoles, ${ }^{21}$ and most recently benzimidazoles ${ }^{22}$ through the judicious choice of conditions and nucleophiles. Carbon monoxide is an inexpensive and important starting material for the industrial production.

To extend this chemistry to polymerization, we developed a novel carbonylation polycondensation for the synthesis of polyamides or polyesters from carbon monoxide, aromatic dibromides, and diamines or bis(phenol)s in the presence of palladium catalysts. ${ }^{23-25}$ Perry and coworkers also reported the syntheses of polyamides, ${ }^{26,27}$ poly(amide-ol)s, ${ }^{28}$ poly(imide-amide)s, ${ }^{29,30}$ and polyimides ${ }^{31}$ based on the carbonylation and con- densation of diiodo compounds and aromatic diamines. Polyimides could be obtained from carbon monoxide and aromatic tetraiodides, instead of diiodides, with diamines. ${ }^{32,33}$ The use of palladium catalysts in the synthesis of poly(ether-ketone-amide)s through polycondensation of aromatic dibromides containing ether ketone structure, aromatic diamines, and carbon monoxide was described by Ueda et al ${ }^{34}$ We found that the reactions of hydrazide as nucleophiles with aromatic bromides and carbon monoxide gave excellent yields of acylhydrazides and poly(acylhydrazide)s could be readily prepared from dihydrazides, aromatic dibromide, and carbon monoxide using this novel reaction. ${ }^{35}$

During the course of our investigation on carbonylation polycondensation, the use of amides was found to lead to the synthesis of linear imides. This article investigates a novel reaction for forming aromatic linear imides through the palladium-catalyzed carbonylation condensation of aromatic amides with aromatic bromides and synthesis of linear polyimides possessing free imide bonds (Scheme 1).

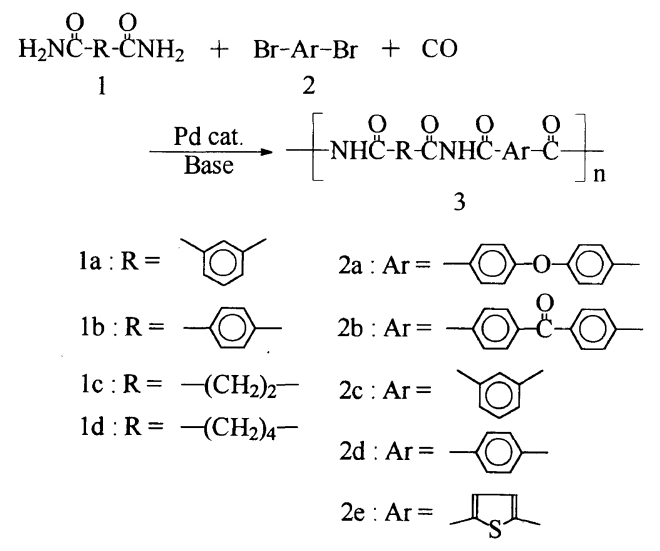

Scheme 1.

To whom correspondence should be addressed. 


\section{EXPERIMENTAL}

\section{Materials}

Benzamide, isophthalamide (1a), 4,4'-dibromodiphenyl ether (2a), and 1,4-dibromobenzene (2d) were recrystallized from ethanol. Bromobenzene, 1,3-dibromobenzene (2c), 2,5-dibromothiophene (2e), 1,5-diazabicyclo[4.3.0]-5-nonene (DBN), and 1,8-diazabicyclo[5.4.0]-7undecene (DBU) were purified by vacuum distillation. 1,4-Diazabicyclo[2.2.2] octane (DABCO) and 7-methyl1,5,7-triazabicyclo[4.4.0]-5-decene (MTBD) were used as received. Sodium hydride was dried in vacuo after washing with dry hexane.

4,4'-Dibromobenzophenone was prepared by the reported procedure. ${ }^{36}$

Carbon monoxide, palladium acetate, and palladium chloride were used as received. 1,2-Bis(diphenylphosphino)ethane (dppe), 1,3-bis(diphenylphosphino)propane (dppp), and 1,4-bis(diphenylphosphino)butane (dppb) were recrystallized from ethanol. Triphenylphosphine $\left(\mathrm{PPh}_{3}\right)$ was recrystallized from hexane. Dichlorobis(triphenylphosphine)palladium $\left[\mathrm{PdCl}_{2}\left(\mathrm{PPh}_{3}\right)_{2}\right]{ }^{37}$ dichlorobis(benzonitrile)palladium $\left[\mathrm{PdCl}_{2}(\mathrm{PhCN})_{2}\right],{ }^{38} \mathrm{di}-$ chloro[1,2-bis(diphenylphosphino)ethane]palladium $\left[\mathrm{PdCl}_{2} \mathrm{dppe}\right]{ }^{39}$ dichloro[1,3-bis(diphenylphosphino)propane]palladium $\left[\mathrm{PdCl}_{2} \mathrm{dppp}\right],{ }^{39}$ and dichloro[1,4bis(diphenylphosphino)butane]palladium $\left[\mathrm{PdCl}_{2} \mathrm{dppb}\right]^{40}$ were prepared by the reported procedures.

Solvents such as $N, N$-dimethylformamide (DMF), $N, N$-dimethylacetamide (DMAc), 1,3-dimethyl-2-imidazolidone (DMI), $N$-methyl-2-pyrrolidone (NMP), and dimethyl sulfoxide (DMSO) were purified by vacuum distillation. Pyridine was purified by distillation.

\section{Model Reaction}

An ordinary catalytic reduction apparatus with gas burette was used as the reaction apparatus. ${ }^{23}$ In a three-necked flask equipped with a stirrer, a carbon monoxide inlet, and a reflux condenser were placed $0.3026 \mathrm{~g}(2.5 \mathrm{mmol})$ of benzamide, $0.3925 \mathrm{~g}(2.5 \mathrm{mmol})$ of bromobenzene, $0.1052 \mathrm{~g}(0.15 \mathrm{mmol})$ of $\mathrm{PdCl}_{2}\left(\mathrm{PPh}_{3}\right)_{2}$, $0.7361 \mathrm{~g}(0.90 \mathrm{mmol})$ of $\mathrm{PPh}_{3}$, and $7.5 \mathrm{~mL}$ of DMAc. The flask was purged several times with carbon monoxide and then heated with stirring at $115^{\circ} \mathrm{C}$ in an oil bath. To the mixture, $0.36 \mathrm{~mL}(2.5 \mathrm{mmol})$ of MTBD was added all at once with a syringe. The reaction mixture was stirred at $115^{\circ} \mathrm{C}$ until consumption of carbon monoxide was complete. The reaction solution was poured into $350 \mathrm{~mL}$ of distilled water. The precipitate was filtered and dried at room temperature in vacuo. The yield was $0.4056 \mathrm{~g}(72 \%)$.

$\mathrm{mp}: 145-146^{\circ} \mathrm{C}$ (lit. $\left.{ }^{41} 145^{\circ} \mathrm{C}\right)$.

Infrared (IR) $(\mathrm{KBr}): 3250 \mathrm{~cm}^{-1}(\mathrm{~N}-\mathrm{H}), 1700 \mathrm{~cm}^{-1}$ $(\mathrm{C}=\mathrm{O})$.

${ }^{1} \mathrm{H}$ NMR (DMSO- $\left.d_{6}\right): 7.51(\mathrm{t}, 4 \mathrm{H}, \mathrm{Ph}-), 7.61(\mathrm{t}, 2 \mathrm{H}$, $\mathrm{Ph}-), 7.94(\mathrm{~d}, 4 \mathrm{H}, \mathrm{Ph}-), 11.21(\mathrm{~s}, 1 \mathrm{H},-\mathrm{CONHCO}-) .{ }^{13} \mathrm{C}$ NMR (DMSO- $\left.d_{6}\right): 128.07,128.30,132.21,133.72(\mathrm{Ph}-)$, $167.42(\mathrm{C}=\mathrm{O})$.

\section{Polymerization}

A typical polymerization is as follows. In a threenecked flask equipped with a stirrer, a carbon monoxide inlet, and a reflux condenser were placed $0.2052 \mathrm{~g}$
(1.25 mmol) of isophthalamide (1a), $0.4100 \mathrm{~g}(1.25 \mathrm{mmol})$ of 4,4'-dibromodiphenyl ether (2a), $0.0526 \mathrm{~g} \quad(0.075$ $\mathrm{mmol})$ of $\mathrm{PdCl}_{2}\left(\mathrm{PPh}_{3}\right)_{2}, 0.5901 \mathrm{~g}(2.25 \mathrm{mmol})$ of $\mathrm{PPh}_{3}$, and $7.5 \mathrm{~mL}$ of DMAc. The flask was purged several times with carbon monoxide and heated with stirring at $130^{\circ} \mathrm{C}$ in an oil bath. To the mixture, $0.43 \mathrm{~mL}(3.0 \mathrm{mmol})$ of MTBD was added all at once with a syringe. The polymerization solution was stirred at $130^{\circ} \mathrm{C}$ until complete consumption of carbon monoxide and then poured into $400 \mathrm{~mL}$ of methanol to precipitate the polymer. The white polymer was filtered and dried at room temperature in vacuo. The yield was $0.2627 \mathrm{~g}(68 \%)$. The inherent viscosity of the polymer was $0.13 \mathrm{dL} \mathrm{g}^{-1}$, measured at a polymer concentration of $0.5 \mathrm{~g} \mathrm{dL}^{-1}$ in DMAc at $30^{\circ} \mathrm{C}$.

IR $(\mathrm{KBr}): 1734 \mathrm{~cm}^{-1}(\mathrm{C}=\mathrm{O})$.

${ }^{1} \mathrm{H}$ NMR (DMSO- $\left.d_{6}\right): 7.19(4 \mathrm{H},-\mathrm{O}-\mathrm{Ph}-\mathrm{CO}-), 7.66$ $(1 \mathrm{H},-\mathrm{CO}-\mathrm{Ph}-\mathrm{CO}-), 8.01(4 \mathrm{H},-\mathrm{O}-\mathrm{Ph}-\mathrm{CO}-), 8.12(2 \mathrm{H}$, $\mathrm{CO}-\mathrm{Ph}-\mathrm{CO}-), 8.42(1 \mathrm{H},-\mathrm{CO}-\mathrm{Ph}-\mathrm{CO}-), 11.45(2 \mathrm{H}$, $-\mathrm{CONHCO}-) .{ }^{13} \mathrm{C}$ NMR (DMSO- $\left.d_{6}\right): 118.52,128.69$, $131.45,159.40$ (-O-Ph-CO-), 129.28, 132.53, 134.05, 159.40 (-CO-Ph-CO-), 166.77, 167.16 (-CONHCO-).

Anal. Calcd for $\left(\mathrm{C}_{22} \mathrm{H}_{14} \mathrm{~N}_{2} \mathrm{O}_{5}\right)_{n}: \mathrm{C}, 68.39 \% ; \mathrm{H}, 3.65$ $\%$; N $7.25 \%$. Found: C, $66.83 \%$; H, $4.20 \%$; , $6.61 \%$.

\section{Measurement}

IR spectra were obtained on a JASCO FT/IR-5000 Fourier transform infrared spectrophotometer. ${ }^{1} \mathrm{H}$ NMR and ${ }^{13} \mathrm{C}$ NMR were recorded on a JEOL JNM-A500 NMR spectrometer in DMSO- $d_{6}$.

\section{RESULTS AND DISCUSSION}

\section{Model Reaction}

Imides are usually prepared by the attack of amides or their salts on acyl halides, anhydrides, and carboxylic acids or esters. ${ }^{42}$ The best synthetic method for the preparation of linear imides is the reaction of an amide with an anhydride in the presence of sulfuric acid. Ban et al. reported that cyclic imides such as phthalimides are formed using palladium-catalyzed carbonylation of $o$-bromobenzamides with carbon monoxide, involving only a single carbon monoxide insertion. ${ }^{43}$ Perry et al. developed a synthetic method for the preparation of $N$-substituted phthalimides involving the palladiumcatalyzed carbonylation, coupling, and cyclization of diiodo aromatics and primary amines. ${ }^{20}$ However the preparation of linear imides has not been reported. To understand the reactivity of aromatic amides in the carbonylation and coupling reaction, the palladiumcatalyzed reactions of benzamide with bromobenzene and carbon monoxide were examined (Scheme 2).

An equimolar solution of benzamide and bromobenzene in DMAc was treated with $6 \mathrm{~mol} \%$ of $\mathrm{PdCl}_{2}$ $\left(\mathrm{PPh}_{3}\right)_{2}, 12 \mathrm{~mol} \%$ of $\mathrm{PPh}_{3}$, and 1.0 equiv. of various organic bases under carbon monoxide at $115^{\circ} \mathrm{C}$ for $2 \mathrm{~h}$ (Table I). Analysis by infrared, ${ }^{1} \mathrm{H}$ and ${ }^{13} \mathrm{C}$ NMR spectroscopy, and melting temperature of the product indicated dibenzoylamine could be prepared except for DABCO. The consumption of carbon monoxide was very slow when using DABCO. MTBD and $\mathrm{NaH}$ were more effective catalysts to afford only dibenzoylamine in $61 \%$ within $2 \mathrm{~h}$. 


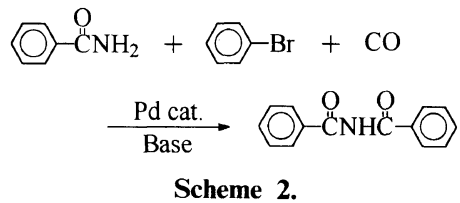

Table I. Effects of a base on the synthesis of dibenzoylamine from benzamide and bromobenzene ${ }^{a}$

\begin{tabular}{lc}
\hline Base & Yield $/ \%$ \\
\hline DABCO & 0 \\
DBN & 19 \\
DBU & 53 \\
MTBD & 61 \\
NaH & 61 \\
\hline
\end{tabular}

${ }^{\text {a }}$ Reaction was carried out with benzamide $(2.5 \mathrm{mmol})$ and bromobenzene $(2.5 \mathrm{mmol})$ in DMAc $(7.5 \mathrm{~mL})$ in the presence of $\mathrm{PdCl}_{2}\left(\mathrm{PPh}_{3}\right)_{2}(0.075 \mathrm{mmol}), \mathrm{PPh}_{3}(0.75 \mathrm{mmol})$, and base $(2.5 \mathrm{mmol})$ at $115^{\circ} \mathrm{C}$ under carbon monoxide.

Table II. Effects of a base on carbonylation polycondensation ${ }^{\mathrm{a}}$

\begin{tabular}{lcc} 
& Yield & $\eta_{\text {inh }}{ }^{\mathrm{b}}$ \\
\cline { 2 - 3 } Base & $\%$ & $\mathrm{dLg}^{-1}$ \\
\hline NaH & 0 & - \\
DBN & 10 & 0.11 \\
DBU & 26 & 0.09 \\
MTBD & 59 & 0.11
\end{tabular}

a Polymerization was carried out with diamide $(1.25 \mathrm{mmol})$ and dibromide $(1.25 \mathrm{mmol})$ in DMAc $(7.5 \mathrm{~mL})$ in the presence of $\mathrm{PdCl}_{2}\left(\mathrm{PPh}_{3}\right)_{2}(0.075 \mathrm{mmol}), \mathrm{PPh}_{3}(0.75 \mathrm{mmol})$, and base $(3.0 \mathrm{mmol})$ at $130^{\circ} \mathrm{C}$ under carbon monoxide. ${ }^{\mathrm{b}}$ Inherent viscosity was measured at polymer concentration of $0.5 \mathrm{~g} \mathrm{dL}^{-1}$ in DMAc at $30^{\circ} \mathrm{C}$.

During the reaction using $12 \mathrm{~mol} \%$ of $\mathrm{PPh}_{3}$, the separation of palladium black was observed. The palladium black would be formed by the disproportionation of the zero-valent palladium, which could be depressed by the addition of $\mathrm{PPh}_{3}$. A six-fold excess of $\mathrm{PPh}_{3}$ to palladium catalyst by mole to the reaction mixture prevented the above problem and increased the yield of dibenzoylamine to $72 \%$.

These results confirm that aromatic amides act as nucleophiles for the carbonylation and coupling reaction.

\section{Polymerization}

On the basis of above results, we prepared linear polyimides 3aa from isophthalamide 1a, 4,4'-dibromodiphenyl ether $\mathbf{2 a}$, and carbon monoxide in the presence of a palladium catalyst and a base. The polymerization apparatus and procedure were the same as those used in the model reaction.

For the carbonylation and coupling reaction, a base is required to neutralize the hydrogen bromide produced as by-products. The influence of bases on the carbonylation polymerization was first studied (Table II). A theoretical volume of carbon monoxide was consumed within $2 \mathrm{~h}$ for all polymerizations. However, $\mathrm{NaH}$ gave no polymer in contrast to the model reaction. MTBD was the most effective of these bases, judging from the yield of polyimide. Figure 1 shows the effect of amount

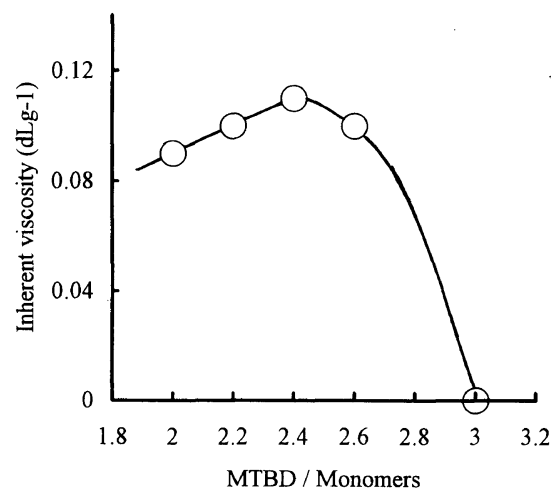

Figure 1. Effects of amount of MTBD on inherent viscosity of the polymer formed by the carbonylation polycondensation of $\mathbf{1 a}$ with $\mathbf{2 a}$ at $130^{\circ} \mathrm{C}$.

Table III. Effects of palladium catalyst on carbonylation polycondensation $^{\mathbf{a}}$

\begin{tabular}{|c|c|c|}
\hline \multirow{2}{*}{ Palladium Catalyst } & Yield & $\eta_{\text {inh }}{ }^{b}$ \\
\hline & $\%$ & $\mathrm{dLg}^{-1}$ \\
\hline $\mathrm{PdCl}_{2}\left(\mathrm{PPh}_{3}\right)_{2}$ & 0 & - \\
\hline $\mathrm{PdCl}_{2}\left(\mathrm{PPh}_{3}\right)_{2} / 10 \mathrm{PPh}_{3}$ & 59 & 0.12 \\
\hline $\mathrm{PdCl}_{2} / 12 \mathrm{PPh}_{3}$ & 0 & - \\
\hline $\mathrm{Pd}(\mathrm{OAc})_{2} / 12 \mathrm{PPh}_{3}$ & 0 & - \\
\hline $\mathrm{PdCl}_{2}(\mathrm{PhCN})_{2} / 12 \mathrm{PPh}_{3}$ & 35 & 0.08 \\
\hline $\mathrm{PdCl}_{2} \mathrm{dppe} / 5 \mathrm{dppe}$ & 0 & - \\
\hline $\mathrm{PdCl}_{2} \mathrm{dppp} / 5 \mathrm{dppp}$ & 0 & - \\
\hline $\mathrm{PdCl}_{2} \mathrm{dppb} / 5 \mathrm{dppb}$ & 0 & - \\
\hline
\end{tabular}

${ }^{\text {a }}$ Polymerization was carried out with diamide $(1.25 \mathrm{mmol})$ and dibromide $(1.25 \mathrm{mmol})$ in DMAc $(7.5 \mathrm{~mL})$ in the presence of Pd catalyst $(0.075 \mathrm{mmol})$ and MTBD $(3.0 \mathrm{mmol})$ at $130^{\circ} \mathrm{C}$ under carbon monoxide. ${ }^{\mathrm{b}}$ Inherent viscosity was measured at polymer concentration of $0.5 \mathrm{~g} \mathrm{dL}^{-1}$ in DMAc at $30^{\circ} \mathrm{C}$.

of MTBD on the inherent viscosity of the polymer. Although a theoretical amount of the base required for the polymerization was 2 equiv. on the base of the bifunctinal monomers, slight excess MTBD was necessary to obtain a higher inherent viscosity. 3.0 equiv. amount afforded no polymer, because the coordination of excessive MTBD would cause steric hindrance to retard the reaction.

Table III summarizes the catalytic effects of palladium complexes on carbonylation polycondensation. Among the catalysts employed, only $\mathrm{PdCl}_{2}\left(\mathrm{PPh}_{3}\right)_{2}$ coupled with a ten-fold excess of $\mathrm{PPh}_{3}$ gave better result with respect of yield and inherent viscosity of the polymer obtained. Other palladium catalysts except for $\mathrm{PdCl}_{2}(\mathrm{PhCN})_{2}$ gave no polymer, as the actual reaction rate was so slow that the precipitation of palladium black occurred before the complete polymerization, judging from the consumption volume of carbon monoxide. Figure 2 shows the influence of amount of $\mathrm{PdCl}_{2}\left(\mathrm{PPh}_{3}\right)_{2}$ on the inherent viscosity of the polyimide. Only $3 \mathrm{~mol} \%$ of palladium catalyst gave no polymer. At 5-6 mol\% catalytic level based on the monomers, the highest inherent viscosity of polyimide was obtained. More than $8 \mathrm{~mol} \%$ decreased the molecular weight of the polymer. These observations are different from those reported in other carbonylation polycondensations. ${ }^{23,25,35}$

The separation of palladium black was also observed 


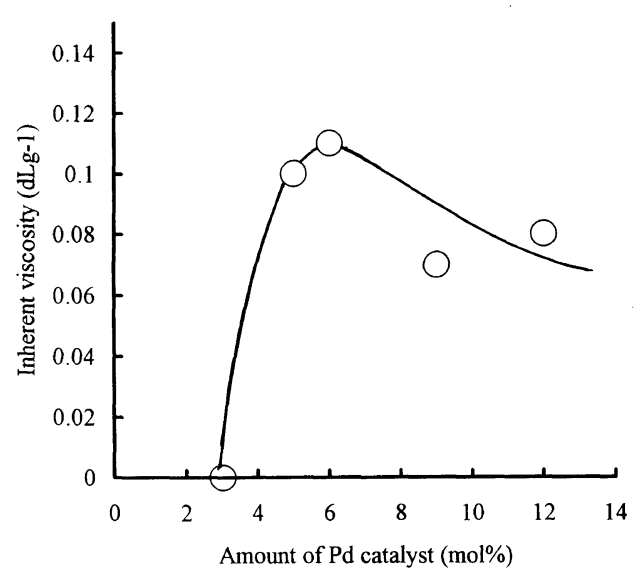

Figure 2. Effects of amount of $\mathrm{PdCl}_{2}\left(\mathrm{PPh}_{3}\right)_{2}$ on the inherent viscosity of the polymer formed by the carbonylation polycondensation of $1 \mathrm{a}$ with $2 \mathrm{a}$ at $130^{\circ} \mathrm{C}$.

Table IV. Effects of amount of triphenylphosphine on carbonylation polymerization ${ }^{\mathrm{a}}$

\begin{tabular}{ccc}
\hline & Yield & $\frac{\eta_{\text {inh }}{ }^{\mathrm{b}}}{\mathrm{PPh}_{3} / \text { Pd cat. }}$ \\
\cline { 2 - 3 } & $\%$ & $\mathrm{dLg}^{-1}$ \\
\hline 6 & 0 & $-{ }^{\mathrm{c}}$ \\
10 & 59 & $0.12^{\mathrm{c}}$ \\
30 & 60 & $0.10^{\mathrm{c}}$ \\
40 & 56 & 0.13 \\
50 & 51 & 0.10 \\
60 & 15 & 0.11 \\
& 22 & 0.10 \\
\hline
\end{tabular}

${ }^{\text {a }}$ Polymerization was carried out with diamide $(1.25 \mathrm{mmol})$ and dibromide $(1.25 \mathrm{mmol})$ in DMAc $(7.5 \mathrm{~mL})$ in the presence of $\mathrm{PdCl}_{2}\left(\mathrm{PPh}_{3}\right)_{2}(0.075 \mathrm{mmol})$ and MTBD $(3.0 \mathrm{mmol})$ at $130^{\circ} \mathrm{C}$ under carbon monoxide. ${ }^{\mathrm{b}}$ Inherent viscosity was measured at polymer concentration of $0.5 \mathrm{~g} \mathrm{dL}^{-1}$ in DMAc at $30^{\circ} \mathrm{C}$. ${ }^{\mathrm{c}}$ Precipitation of palladium black was observed.

during the polymerization, even though a six-fold excess of $\mathrm{PPh}_{3}$ to palladium catalyst by mole was added to the polymerization mixture. The effects of ratio of $\mathrm{PPh}_{3}$ to $\mathrm{PdCl}_{2}\left(\mathrm{PPh}_{3}\right)_{2}$ were studied to solve this problem (Table IV). Large excess $\mathrm{PPh}_{3}$ was required to prevent the precipitation of palladium black, though the yield of the polymer decreased using more than 50-fold excess of $\mathrm{PPh}_{3}$. On the other hand, the molecular weight of the polymer prepared in homogeneous solution was not affected.

The polymerizations were carried out between 100 and $150^{\circ} \mathrm{C}$. Increasing polymerization temperature was not effective for increasing the inherent viscosity of the polyimide. At a higher temperature of $150^{\circ} \mathrm{C}$, no polymer was prepared because the volume of carbon monoxide dissolved in the polymerization mixture decreased similarly to previous reports. ${ }^{23,24,35}$

The influence of the polymerization medium on the inherent viscosity of the polymer is shown in Table V. Among the solvents used, only DMAc was the suitable solvent for the carbonylation polycondensation with higher yield.

The polymer obtained was confirmed to be the corresponding linear polyimide 3aa by means of IR, NMR spectroscopy, and elementary analysis. The IR spectrum exhibited a characteristic carbonyl absorption band
Table V. Effect of solvent on carbonylation polycondensation ${ }^{\mathbf{a}}$

\begin{tabular}{lcc}
\hline & Yield & $\frac{\eta_{\text {inh }}{ }^{\mathrm{b}}}{2}$ \\
\cline { 2 - 2 } Solvent & $\%$ & $\mathrm{dL} \mathrm{g}^{-1}$ \\
\hline DMF & 33 & 0.09 \\
DMAc & 59 & 0.11 \\
DMI & trace & - \\
NMP & 34 & 0.09 \\
DMSO & 0 & - \\
Pyridine & 0 & -
\end{tabular}

a Polymerization was carried out with diamide $(1.25 \mathrm{mmol})$ and dibromide $(1.25 \mathrm{mmol})$ in a solvent $(7.5 \mathrm{~mL})$ in the presence of $\mathrm{PdCl}_{2}\left(\mathrm{PPh}_{3}\right)_{2}(0.075 \mathrm{mmol}), \mathrm{PPh}_{3}(0.75 \mathrm{mmol})$, and MTBD $(3.0 \mathrm{mmol})$ at $130^{\circ} \mathrm{C}$ under carbon monoxide. ${ }^{\mathrm{b}}$ Inherent viscosity was measured at polymer concentration of $0.5 \mathrm{~g} \mathrm{dL}^{-1}$ in DMAc at $30^{\circ} \mathrm{C}$. ${ }^{\mathrm{c}}$ Polymerization temperature was $115^{\circ} \mathrm{C}$.

Table IV. Preparation of linear polyimides ${ }^{\mathrm{a}}$

\begin{tabular}{cccc}
\hline & & \multicolumn{1}{c}{ Yield } & $\eta_{\text {inh }}{ }^{\mathbf{b}}$ \\
\cline { 3 - 4 } & & $\mathbf{0}$ & $\mathrm{dLg}^{-1}$ \\
\hline $\mathbf{1 a}$ & $\mathbf{2 a}$ & 59 & 0.11 \\
$\mathbf{1 a}$ & $\mathbf{2 b}$ & 43 & 0.09 \\
$\mathbf{1 a}$ & $\mathbf{2 c}$ & 13 & 0.09 \\
$\mathbf{1 a}$ & $\mathbf{2 d}$ & 26 & 0.09 \\
$\mathbf{1 a}$ & $\mathbf{2 e}$ & trace & - \\
$\mathbf{1 b}$ & $\mathbf{2 a}$ & 10 & - \\
$\mathbf{1 c}$ & $\mathbf{2 a}$ & trace & - \\
$\mathbf{1 d}$ & $\mathbf{2 a}$ & trace & -
\end{tabular}

${ }^{\text {a }}$ Polymerization was carried out with diamide $(1.25 \mathrm{mmol})$ and dibromide $(1.25 \mathrm{mmol})$ in DMAc $(7.5 \mathrm{~mL})$ in the presence of $\mathrm{PdCl}_{2}\left(\mathrm{PPh}_{3}\right)_{2}(0.075 \mathrm{mmol}), \mathrm{PPh}_{3}(0.75 \mathrm{mmol})$, and MTBD $(3.0 \mathrm{mmol})$ at $130^{\circ} \mathrm{C}$ under carbon monoxide. ${ }^{b}$ Inherent viscosity was measured at polymer concentration of $0.5 \mathrm{~g} \mathrm{dL}^{-1}$ in DMAc at $30^{\circ} \mathrm{C}$.

of linear imides at $1734 \mathrm{~cm}^{-1}$. The ${ }^{1} \mathrm{H}$ NMR spectrum of the polymer exhibits a characteristic peak of imide protons at $11.45 \mathrm{ppm}$. In ${ }^{13} \mathrm{C}$ NMR spectrum, all peaks could be assigned to polymer 3aa and amide end groups. However, there is a slight difference between calculated values and found values in the elementary analysis, because of the influence of end groups.

Based on these findings, various linear polyimides 3 were prepared from aromatic diamides $(\mathbf{1 a}, \mathbf{1 b})$ or aliphatic diamides (1c, 1d), aromatic dibromides $(\mathbf{2 a -}-\mathbf{e})$, and carbon monoxide under the polymerization conditions obtained above. The results are listed in Table VI. The polymerization of 1 a with $\mathbf{2 e}$ gave no polymer, though consumption of carbon monoxide was observed. When using aliphatic diamide 1c or 1d with dibromide $\mathbf{2 a}$, polymerization did not proceed, because of no consumption of carbon monoxide. The yield and molecular weight of the polymer 3aa, 3ab, 3ac, 3ad obtained were not enough, even if the polymerizations were carried out for longer time.

\section{CONCLUSIONS}

Amides have enough activity as nucleophiles in palladium-catalyzed carbonylation and coupling reaction to afford readily diaroylamines without triaroylamines. The synthesis of linear polyimides with free imide bonds was achieved by palladium-catalyzed carbonylation poly- 
condensation of isophthalamide and aromatic dibromides with carbon monoxide. Other aromatic diamides did not have suitable activity for the carbonylation polycondensation and aliphatic diamides have no abilities.

Acknowledgments. This work was partially supported by the Grants-in-Aid for Scientific Research (No. 06750902) from the Ministry of Education, Science, Sports and Culture of Japan and Tokuyama Science Foundation.

\section{REFERENCES}

1. A. W. Wilson and T. T. Serafini, in "Polyimides," K. L. Mittal, Ed., Plenum, New York, N.Y., 1984.

2. D. Wilson, H. D. Stenzenberger, and P. M. Hergenrother, in "Polyimides," Champman and Hall, New York, N.Y., 1990.

3. K. Kurita, M. Yamakawa, and Y. Koyama, Chem. Lett., 2337 (1987).

4. K. Kurita, M. Yamakawa, K. Iida, E. Susa, and Y. Koyama, $J$. Polym. Sci., Part A, Polym. Chem. Ed., 27, 4297 (1989).

5. Y. Saegusa, A. Inoo, and S. Nakamura, Polym. J., 25, 1099 (1993).

6. K. H. Park, S. Watanabe, M. Kakimoto, and Y. Imai, Polym. Prepr., Jpn., 42, 482 (1993).

7. A. Schoengerg, I. Bartoletti, and R. F. Heck, J. Org. Chem., 39, 3318 (1974)

8. A. Schoenberg and R. F. Heck, J. Org. Chem., 39, 3327 (1974).

9. F. Ozawa, H. Soyama, T. Yamamoto, and A. Yamamoto, Tetrahedron Lett., 23, 3383 (1982).

10. F. Ozawa and A. Yamamoto, Chem. Lett., 865 (1982).

11. F. Ozawa, H. Soyama, H. Yanagihara, I. Aoyama, H. Takino, K. Izawa, T. Yamamoto, and A. Yamamoto, J. Am. Chem. Soc., 107, 3235 (1985)

12. M. Tanaka, T. A. Kobayashi, F. Sakakura, N. Itatani, S. Danno, and K. Zushi, J. Mol. Catal., 32, 115 (1985).

13. F. Ozawa, N. Kawasaki, T. Yamamoto, and A. Yamamoto, Chem. Lett., 567 (1985).

14. B. Morin, A. Hirschauer, F. Hughes, D. Commereuc, and Y. Chauvin, J. Mol. Catal., 34, 317 (1986).

15. I. Pri-Bar and H. Alpher, J. Org. Chem., 54, 36 (1989).

16. T. Sakakura, M. Chaisupakitsin, T. Hayashi, and M. Tanaka, $J$. Organomet. Chem., 334, 205 (1987).
17. Y. Mori, K. Chiba, and Y. Ban, J. Org. Chem., 43, 1684 (1978).

18. L. D. Martin and J. K. Stille, J. Org. Chem., 47, 3630 (1982)

19. M. Tanaka, Tetrahedron Lett., 2601 (1979).

20. R. J. Perry and S.R. Turner, J. Org. Chem., 56, 6573 (1991).

21. R. J. Perry, B.D. Wilson, and R. J. Miller, J. Org. Chem., 57, 2883 (1992)

22. R.J. Perry and B.D. Wilson, J. Org. Chem., 58, 7016 (1993).

23. M. Yoneyama, M. Kakimoto, and Y. Imai, Macromolecules, 21, 1908 (1988).

24. M. Yoneyama, M. Kakimoto, and Y. Imai, J. Polym. Sci., Part A, Polym. Chem. Ed., 27, 1985 (1989).

25. M. Yoneyama, M. Kakimoto, and Y. Imai, Macromolecules, 22, $2593(1989)$

26. S. R. Turner, R. J. Perry, and R. W. Blevins, Macromolecules, 25, 4819 (1992)

27. R. J. Perry, S. R. Turner, and R. W. Blevins, Macromolecules, 26, 1509 (1993)

28. R. J. Perry and B. D. Wilson, Macromolecules, 27, 40 (1994)

29. R. J. Perry, S. R. Turner, and R. W. Blevins, Macromolecules, 27, 4058 (1994).

30. R. J. Perry, S. R. Turner, and R. W. Blevins, Macromolecules, 28, 2607 (1995)

31. R. J. Perry, B. D. Wilson, S. R. Turner, and R. W. Blevins, Macromolecules, 28, 3509 (1995).

32. R. J. Perry and S.R. Turner, J. Macromol. Sci.-Chem., A28, 1213 (1991).

33. R. J. Perry and S.R. Turner, Makromol. Chem., Macromol. Symp., 54/55, 159 (1992).

34. M. Ueda and T. Yokoo, J. Polym. Sci., Part A, Polym. Chem. Ed., 32, 2065 (1994).

35. M. Yoneyama, M. Kakimoto, and Y. Imai, Macromolecules, 22 , 4152 (1989)

36. M. Bochmann and K. Kelly, J. Polym. Sci., Part A, Polym. Chem. Ed., 30, 2503 (1992).

37. R. F. Heck, in "Palladium Reagents in Organic Syntheses," Academic, New York, N.Y., 1985, p 18.

38. J. R. Doyle, P. E. Slade, and H. B. Jonassen, Inorg. Synth., 6, 218 (1960).

39. W. L. Steffen and G. J. Paleik, Inorg. Synth., 15, 2432 (1976).

40. M. Tanaka, T. Kobayashi, and T. Sakakura, Nippon Kagaku Kaishi, 537 (1985).

41. C. Yajima, F. Hino, and K. Suda, Synthesis, 610 (1981).

42. B.C. Challis and J. Challis, in "The Chemistry of Amides," J. Zabicky, Ed., John Wiley and Sons, New York, N.Y., 1970, p 759.

43. M. Mori, K. Chiba, N. Ohta, and Y. Ban, Heterocycles, 13, 329 (1979). 